\title{
LA ONTOLOGÍA SOCIAL Y EL CÍRCULO VIRTUOSO DE LA EDUCACIÓN PÚBLICA
}

\author{
Rodrigo A. González F. \\ Maria Soledad Krause $M .^{2}$
}

\begin{abstract}
RESUMEN: En este artículo argumentamos que la naturaleza pública o privada de la educación tiene una incidencia directa en las instituciones que conforman la realidad social. Para sustentar lo anterior, en primer lugar discutimos cómo, según Searle, habitamos un mundo de instituciones gobernadas por reglas y poderes deónticos, ontológicamente irreductibles. Luego, postulamos que la intencionalidad colectiva requiere de la confianza para mantenerse, y esta aumenta cuando gobiernan reglas y poderes deónticos en circunstancias normales. Finalmente, planteamos que la educación pública es una institución que, a diferencia de la privada, privilegia el espacio de lo común. Sócrates es un ejemplo de esto, al proponer una filosofía que no solo busca la verdad, sino que además privilegia el reconocimiento de la ley por sobre la satisfacción inmediata de deseos e inclinaciones personales. De todo esto se explica el círculo virtuoso: la educación pública, al ser inclusiva y beneficiar a todos, potencia las instituciones sociales que tutelan ese interés y, dentro de ellas, el servicio público.
\end{abstract}

Palabras Clave: Educación pública. Poderes deónticos. Instituciones. Razones institucionales.

Nosotras las leyes te hemos engendrado, criado, educado y te hemos hecho partícipe, como a todos los demás ciudadanos, de todos los bienes de que éramos capaces...

Las Leyes, en Critón

${ }^{1}$ Director del Centro de Estudios Cognitivos y Profesor Asistente del Departamento de Filosofía de la Facultad de Filosofía y Humanidades, Universidad de Chile, Santiago - Chile, en materias de Filosofía de la Mente y de la Inteligencia Artificial, y de Ontología Social. E-mail: rodgonfer@gmail.com

Licenciado en Humanidades con mención en Filosofía y Magíster en Filosofía por la Universidad de Chile. Master in Philosophy and PhD in Philosophy por la Katholieke Universiteit Leuven.

2 Profesora de la Escuela de Derecho de la Universidad Católica de Chile, Santiago - Chile, en las materias de derecho penal y derecho administrativo penal. E-mail: skrausem@gmail.com

Licenciada en Ciencias Jurídicas y Sociales por la Universidad de Chile, Magister en Filosofía por la Universidad de Chile y Doctora en Derecho Penal y Ciencias Penales en la Universidad Pompeu Fabra.

http://dx.doi.org/10.1590/0101-3173.2018.v41n2.09.p157 


\section{INTRODUCCIÓN}

La educación pública es una institución clave en la sociedad. Gracias a ella la intencionalidad colectiva logra crear un conjunto de instituciones con un afán de permanencia en el tiempo: las instituciones públicas. Estas tienen una naturaleza despersonalizada, orientada al espacio de lo común y, por lo mismo, al beneficio de todos. Por su propia naturaleza, tales instituciones tienden a perpetuarse de una manera independiente de los sujetos concretos que las conforman; de ahí que al margen de quienes sean estos, cumplen sus funciones. Si bien la educación privada también desarrolla las habilidades, capacidades y destrezas de las personas, y, como toda educación, aspira a la consecución y a la transmisión de la verdad, lo hace dentro de un sistema que es producto de una intencionalidad más limitada o menos inclusiva, al servicio de intereses menos representativos o más contingentes. En las instituciones privadas no hay pretensión de permanencia o ella es menor, su afán no es necesariamente inclusivo e institucional, y tienen un carácter más personal, o dependiente de las personas que las conforman, circunstancias todas que determinan que tiendan en menor medida a contribuir a la conformación de esa lógica común.

En vista de la importante diferencia entre educación pública y privada, en este trabajo mostramos de qué forma la primera se relaciona estrechamente con la ontología social, conformando un círculo virtuoso. En la primera sección exponemos de qué forma el ser humano se encuentra inmerso en un mundo de instituciones (SEARLE, 1997, 2010), cuyas complejas estructuras normativas son difícilmente explicables de modo reductivo por ciencias básicas con ontología objetiva. En efecto, las instituciones involucran asignación de funciones y roles, así como regulaciones y poderes deónticos, todo lo cual tiene ontología subjetiva (SEARLE, 2010, p. 18). $\mathrm{Si}$ el sistema social funciona correctamente, se nutre de reglas y poderes, lo que acrecienta la confianza, tópico que discutimos en la segunda sección. Finalmente, en la última, examinamos cómo la educación pública se asocia con la intencionalidad colectiva general. Esta, que afianza y consolida las instituciones públicas cuyo norte es lo colectivo, ayuda a conformar un círculo virtuoso. Tal como destacamos, Sócrates y su defensa de la ley y lo común por sobre lo individual es un ejemplo de cómo la enseñanza pública se orienta al reconocimiento de la ley, al espacio de lo común y, en consecuencia, a la inclusión y al beneficio de todos. 


\section{LA INMERSIÓN TOTAL EN LA REALIDAD SOCIAL}

Según Searle (1997, 2010), no vivimos en dos, tres o más mundos. Vivimos solo en uno, pese a la complejidad que tiene nuestro entorno cotidiano: la realidad social. Esta constituye un locus de la civilización, incluso si su invisibilidad incluye entidades, procesos y relaciones abstractas y complejas, como matrimonios, partidos de fútbol, dinero, gobiernos, y todo lo que requiere del acuerdo colectivo para existir. En efecto, aunque crecemos desde niños en un mundo de juegos, imaginerías e instituciones (RAKOCZY, 2007; RAKOCZY; TOMASELLO, 2008), tres instancias que están íntimamente conectadas con la realidad social "invisible", nos mantenemos inconscientemente inmersos en ella. Esto explica por qué ciertos intentos fisicalistas de entender lo mental (PLACE, 1956; SMART, 1959) como lo cerebral resultan tan cuestionables como la reducción ontológica de lo social a lo puramente material. En efecto, pese a la fuerza de estos argumentos, aprendemos a usar el dinero, a jugar al fútbol y, ciertamente, a ir a la escuela antes que a entender que los objetos físicos no son más que metal, papel o madera. Asimismo, ejercemos nuestra condición de seres sociales antes de entender que somos, junto con los animales, productos biológicos de la evolución.

Ciencias básicas como la química o la biología también resultan problemáticas para elucidar la compleja realidad de las instituciones humanas. Estas disciplinas científicas no explican cómo se pasa de protones a presidentes, o de campos de fuerza a gobiernos. La existencia de sindicatos, corporaciones, dinero, repúblicas y matrimonios no parece reducirse a la mera organización de partículas, de sistemas de campos de fuerza, o bien de la pura evolución humana. El hecho de que tales instituciones, tan cercanas como complejas, den lugar a asombrosos sistemas de reglas, derechos, deberes y jerarquías, punto que retomaremos en la siguiente sección, es ciertamente enigmático si solo se considera la realidad desde lo más simple y objetivo: las partículas físicas.

Hay, de hecho, una característica esencial del ser humano que se revela en la realidad social: junto con la conciencia y la intencionalidad, dos propiedades mentales emergentes causadas por nuestra peculiar biología, hay una dimensión social, colectiva, asociada a como aquél coopera para crear y mantener la cultura y civilización humana. En relación con esta característica, Searle (1997) sostiene que es menester explorar cómo el cerebro origina la 
mente, como esta da lugar al lenguaje y, por último, como este ayuda a crear y mantener la sociedad.

La conciencia y la intencionalidad son esenciales para el funcionamiento de la mente, e indudablemente explicativas del paso de lo mental a lo lingüístico, y de lo lingüístico a lo social. Gracias a la conciencia nos relacionamos con nuestro entorno, y somos capaces de mapear este. A su vez, la intencionalidad hace que seamos capaces de representar, teniendo estados mentales acerca de que nos permiten relacionarnos con el mundo de manera inteligente. Por ejemplo, tenemos creencias que nos capacitan para representar estados de cosas: Juan cree que está lloviendo. O deseos, que involucran qué estados de cosas nos gustaría que se dieran en el mundo: Juan desea ser profesor.

De acuerdo con el naturalismo biológico de Searle, la conciencia y la intencionalidad potencian de modo crucial nuestras capacidades. Sin la conciencia seríamos "robóticos", en el sentido de que no estableceríamos un vínculo de "sintiencia" entre nosotros y el ambiente, con un persistente mapeo del mismo. Un indicio de que esto es correcto es que, a diferencia de los robots, por lo general respetamos conscientemente las reglas de un sistema social. Sin la intencionalidad intrínseca de la mente no tendríamos cómo representar cosas, eventos, propiedades; sin la intencionalidad derivada (SEARLE, 1984, p. 78) no podrían existir el lenguaje, los mapas y las señales, elementos cruciales de la civilización.

Esta, de hecho, se explica por la cooperación entre seres humanos, lo cual da lugar a la intencionalidad colectiva (SEARLE, 1997). A pesar de lo que manifiesta este filósofo, psicólogos cognitivos tales como Rakoczy y Tomasello (2007) afirman que el sentido de la cooperación nos diferencia decisivamente de los animales. Ellos tienen conducta coordinada en pos de alcanzar objetivos concretos, mientras que el ser humano tiene la capacidad de cooperar para realizar labores imposibles de llevarse a cabo individualmente. El clásico ejemplo del matrimonio, por la declaración y el compromiso que involucra, es paradigmático. Cuando se celebra esta ceremonia los cónyuges se prometen lealtad y cooperación mediante la declaración vinculante del contrato, y esta relación se mantiene a través del tiempo, en principio, hasta que la muerte los separe. Justamente, para comprender mejor la existencia de lo institucional en la realidad social es necesario referirse a dos distinciones que este filósofo hace: entre hechos brutos e institucionales, por una parte, y entre la ontología subjetiva y objetiva, por otra. 
Que la luna es el cuarto del diámetro de la Tierra y que es $1 / 81$ de la masa de esta son hechos brutos. En efecto, la ocurrencia de tales hechos no depende de ningún observador; tampoco de alguna institución o de un acuerdo. Acontecerían incluso si no hubiera observadores o acuerdos. Es un hecho institucional, en cambio, que Barack Obama es marido de Michelle Obama. Ambos son cónyuges en virtud de un acuerdo, de un contrato vinculante desde una perspectiva social y colectiva. Si, por ejemplo, desapareciese la raza humana, tal matrimonio dejaría de existir, al igual que otras instituciones como el dinero, el lenguaje, los gobiernos, los parlamentos y las fronteras.

También es importante tener en cuenta que hay objetos cuyo modo de existir no depende de ninguna mente. Según el realismo que defiende Searle, "placa tectónica", por ejemplo, refiere a ciertos objetos con independencia de la humanidad, pese a que los terremotos son catástrofes importantes para esta. La ocurrencia de dichas catástrofes, empero, está ligada al movimiento de las placas, un fenómeno que en nada depende de nosotros para existir. Algo muy diferente ocurre con fenómenos como un dolor de cabeza, que tienen una ontología "especial". El dolor existe para alguien. En este sentido, el dolor se parece a la realidad institucional, porque ambos necesitan de observadores para su existencia; por tanto, tienen ontología subjetiva.

Ahora bien, en la medida que hay un importante elemento de imaginación en la existencia y mantención de la realidad social y, en particular, de la creación y mantención de las instituciones, esto confirma su ontología subjetiva. Nuevamente, en un mundo donde no existiera la humanidad, no existirían instituciones, a no ser, por supuesto, que en dicho mundo hubiera seres con mentes similares a las humanas. Estos podrían acordar colectivamente la existencia de dichas instituciones, y así podrían establecer, mantener y reconocer prácticas reguladas por las mismas.

Es importante destacar que la intencionalidad colectiva: del hacemos, del acordamos, del estipulamos, da origen a la asignación de funciones a objetos (SEARLE, 1997, 2010). Aquella es crucial para que la realidad social emerja con su ontología subjetiva. A diferencia de los animales, los humanos tenemos la capacidad de acordar la asignación de funciones a cosas; esto es la esencia de las denominadas funciones agentivas, entre las cuales destacan las funciones de estatus. Por ejemplo, a un muro de piedras le asignamos la función de dividir territorio, con un límite que impide el ingreso a foráneos. Tales asignaciones son el origen de las instituciones; e.g., asignamos una función a papeles para que cuenten como dinero. También es importante 
recalcar que la asignación de funciones de estatus se rige por la fórmula " $\mathrm{X}$ cuenta como Y en C”. Así, las piedras del muro regulan la existencia de un limite en un contexto determinado.

Gracias a esa fórmula "sacramental" de la creación de instituciones, las propiedades físicas intrínsecas de algunos objetos resultan irrelevantes para que haya funciones de estatus asignadas colectivamente. En el caso de una frontera, por ejemplo, si bien la existencia de un hito o de un muro ayuda a cumplir esa función, no es estrictamente necesaria. Por ejemplo, podría darse el caso de que los habitantes de un territorio acordaran la existencia de una frontera. Por otra parte, el muro puede decaer al punto de que la línea de piedras solo tenga una función simbólica.

Precisamente, el carácter simbólico de las funciones de estatus hace que estas sean dependientes de creencias y de representaciones lingüísticas, elementos que hacen a las mismas irreductibles desde el punto de vista de una ontología objetiva. De este modo, por ejemplo, un hito fronterizo simboliza una función mucho más allá de su mera constitución física, aunque es claro que lo social depende, finalmente, del nivel físico. Si no fuera el caso, lo social podría ser un nivel independiente de lo físico. Ello, ciertamente, contravendría la tesis serleana de que vivimos en un solo mundo.

Pese a la invisibilidad de las instituciones, vivimos inmersos en la realidad social. Esta hace del ser humano el animal más inteligente, en la medida que dispone de instituciones que regulan y posibilitan prácticas y procesos sociales complejos. Habilitar, prohibir, prometer, obligar, poseer propiedad, comprar, vender, arrendar, contratar, subvencionar, entre muchas otras prácticas y procesos sociales complejos nos diferencian crucialmente de los animales, los cuales solo parecen reaccionar frente a los estímulos ambientales; por eso, para sobrevivir, coordinan conducta colectivamente.

A esto se agrega que el ser humano se involucra en la realidad social con un sentido de futuro, esto es, de expectativas que nacen del funcionamiento de instituciones, y también de las posibilidades que otorgan. Las instituciones, que se encuentran reguladas por reglas constitutivas dan lugar a la confianza, tal como analizamos en la sección 2. Ello ocurre porque, en general, las reglas se asocian a derechos y deberes, los poderes deónticos, que potencian o limitan la acción en la realidad social. Finalmente, en virtud de las reglas y poderes es posible apelar a razones institucionales para la acción, al posponer la satisfacción de deseos e inclinaciones personales. 
Un tipo de instituciones nos interesan en particular en este trabajo: las públicas. Ellas nacen producto de la intencionalidad colectiva general y, por lo mismo, están orientadas a lo común y al beneficio de todos. Se trata de instituciones que han pasado a conformar de manera básica la forma misma de lo social. Estado, Presidente de la República, Congreso Nacional, Tribunales, Educación Pública, entre muchas otras. La lógica de lo común, que refleja la intencionalidad colectiva general, es particularmente irreductible en términos físicos y objetivos a propósito de ellas. Así, es imposible entender esas instituciones y el rol que las mismas representan en una sociedad si solo se apela a una ontología objetiva. Más aún, la lógica de lo común, al tener que ver con un espacio para esos fines, refrenda las dificultades detectadas por Searle para reducir la intencionalidad colectiva a la intencionalidad individual (SEARLE, 2010, p. 46-47). Esto es importante para los propósitos de la presente discusión, porque la educación pública es una institución pública que, como analizamos en las secciones venideras, mira precisamente a ese espacio colectivo.

Hasta aquí, hemos analizado por qué el ser humano se encuentra inmerso en la realidad social, la cual es irreductible por una ontología objetiva. Sin embargo, es menester analizar la relación entre expectativas e instituciones. Estas fomentan la confianza y fortalecen las estructuras institucionales en caso de que los poderes deónticos funcionen correctamente. La descripción de tal proceso permitirá comprender mejor el peculiar funcionamiento de las instituciones públicas.

\section{El FUNCIONAMIENTO CORRECTO DE REGLAS Y PODERES DEÓNTICOS: CÓMO GENERAN CONFIANZA Y MANTIENEN ESTRUCTURAS INSTITUCIONALES}

Tal como se examinó en la sección previa, las instituciones están asociadas a actividades propiamente humanas: un sistema en que se crean o regulan prácticas y procesos sociales que no existirían de otra forma. Tal como enfatiza Searle $(1997,2010)$, el portador, por ejemplo, de un billete de $\$ 1$ se sujeta a las reglas constitutivas asociadas a la institución "dinero"; estas le dan derecho a comprar bienes por dicho valor. A su vez, quien tiene un pasaporte está habilitado para viajar al extranjero. Que agentes porten billetes y pasaportes los capacitan para realizar actividades sociales complejas, las cuales están reguladas normativamente en una sociedad. Tales actividades no podrían darse fluidamente sin la tenencia de tales ejemplares institucionales, 
ni tampoco de las reglas constitutivas asociadas. Hay, entonces, una retroalimentación entre las instituciones y la regulación de prácticas en la realidad social. Las instituciones públicas son, como examinamos en esta sección, un ejemplo paradigmático de esto, porque las regulaciones que suponen tienen afán de permanencia en el tiempo, con independencia de las inclinaciones o deseos personales.

La retroalimentación entre instituciones y reglas, junto con la mantención de las primeras por parte de una comunidad, genera expectativas y acciones válidas en los agentes. Es crucial para explicar esa mantención de prácticas, y la estabilidad que conllevan, el funcionamiento de los poderes deónticos ligados a las instituciones. Si bien toda institución es producto del acuerdo colectivo, es decir, de una estipulación de reglas constitutivas de la forma "X cuenta como Y en C", la realidad social no existiría si no hubiera derechos y deberes asociados a las instituciones. Las reglas constitutivas son fundamentales aquí, porque originan un juego o una institución y hacen que se dé en el mundo de manera regulada (por ejemplo, el ajedrez); ello se vincula con los mencionados derechos y deberes. Luego, existe un vínculo entre instituciones, reglas y poderes deónticos, una cuestión típica de las sociedades complejas.

Searle $(1997,2010)$ usa el término poder para los deberes y derechos. Por ejemplo, graduar a una persona de médico cirujano le confiere un rol y, a consecuencia de ello, derechos, tales como expender recetas médicas o la autorización para atender pacientes y realizar procedimientos médicos. Para el mismo también hay poderes deónticos positivos, que genera un deber correlativo del Estado y los demás ciudadanos de crear las condiciones posibles para el ejercicio de los mencionados poderes. A un mismo tiempo, de su rol derivan obligaciones que son, a su vez, derechos para terceros o para el propio Estado, como son, por ejemplo, los de actuar con diligencia y cuidado en la atención de sus pacientes, otorgar licencias médicas solo en los casos en que advierta la existencia de una enfermedad en el paciente que lo amerite, o denunciar determinados hechos de los que conoce en el ejercicio de su profesión. Como queda en claro, la mayor parte de los deberes dan origen a derechos correlativos y viceversa.

Justamente, la tesis que defendemos en esta sección es que cuando los poderes deónticos funcionan correctamente en una sociedad, se fortalecen las estructuras institucionales de un sistema social, y ello genera confianza. Es claro que si los médicos no ejercieran su profesión en virtud de una autorización y 
si los conductores de vehículos no fueran habilitados para manejarlos luego de practicárseles ciertos exámenes, ser atendido por un galeno, o circular en la vía pública serían actividades altamente riesgosas. Luego, se reduce el riesgo en la medida que hay instituciones que facultan a ciertos agentes a desarrollar actividades de acuerdo con determinadas reglas.

En efecto, las actividades de galenos y conductores resultan confiables en la medida que hay ciertos desiderata satisfechos, impuestos por instituciones. Estas, cabe destacar, son fiscalizadas por otras instituciones. La satisfacción de desiderata es clave, porque valida las instituciones, al implicar el reconocimiento de las mismas.

De hecho, que las actividades y prácticas sociales resulten confiables debido al correcto funcionamiento de instituciones incide en el fortalecimiento y mantención de las estructuras institucionales. El funcionamiento de dichas estructuras gracias a los poderes deónticos hace que un sistema social resulte confiable. La confianza, en este preciso sentido, es el lubricante social de prácticas y actividades sociales, porque los agentes tienen expectativas ajustadas a los poderes deónticos, y esto es un elemento facilitador de la acción. Si Juan desea cruzar la calle, pero no confía en que los conductores de automóviles están facultados para conducir y que actuarán en conformidad con las leyes de tránsito, es muy probable que no cruce. $\mathrm{O}$ bien que lo haga temeroso, asumiendo un riesgo, no un derecho. Lo mismo ocurriría con un piloto que no confiara en el personal de tierra para la mantención del avión: arriesgaría no despegar nunca.

Dada la relación entre poderes deónticos y expectativas que defendemos aquí, es posible proponer que la confianza contribuye fundamentalmente a mantener las estructuras institucionales. Tal como se analizó en la primera sección, el ser humano coopera y se asocia para realizar labores imposibles de materializarse individualmente; también para la creación de eventos y situaciones impensables en el reino animal. Pero, lo social, que es un producto de la intencionalidad colectiva, no puede darse sin que los agentes confíen en que cada uno desempeñará el papel que le corresponde en vista de ciertas prácticas, y de acuerdo con las reglas constitutivas correspondientes. A propósito de estas, las reglas del ajedrez configuran acciones válidas de los jugadores; esto hace que sea esperable de un jugador que realice un enroque de acuerdo con las mismas. 
Los ejemplos paradigmáticos que propone Searle de intencionalidad colectiva son simples, tales como la orquesta y el equipo de fútbol. Ambos servirán para argumentar por qué la confianza resulta clave en la realidad social. En el caso de la orquesta, por ejemplo, el primer violinista confía en que el resto de la orquesta lo seguirá. Los otros violinistas, las violas y los vientos también confían que el primer violinista hará lo que le corresponde. En un equipo de fútbol, un arquero confía en que los defensores ayudarán a evitar goles, y que tratarán de marcar en el arco contrario, al igual que el resto del equipo. Este, a su vez, confía en que el arquero hará su parte. Es importante tener en consideración que, tal como Searle recalca (SEARLE, 2010, p. 47-48), que la actividad de miembros de una orquesta o equipo sea individual no involucra que no haya intencionalidad colectiva. Como insiste, los intentos de reducir esta a intencionalidad individual más conocimiento de creencias compartidas fracasan. Este punto lo retomamos en la siguiente sección, a propósito de cómo la educación pública responde a la intencionalidad colectiva general, de la ciudadanía. Y a como, por lo mismo, es una institución pública clave de la realidad social.

Ahora bien, la dinámica entre intencionalidad colectiva, confianza y reglas se vincula crucialmente con lo que Searle llama razones institucionales independientes de deseos (SEARLE, 2010, p. 127-131). Esto es, a operar de acuerdo con reglas que se reconocen como independientes de deseos o inclinaciones personales y, más aún, como elementos suficientes para posponer la satisfacción de las mismas. Por ejemplo, un profesor se dirige a hacer clases a una hora convenida, en vez de dormir una siesta o ir de compras. Un equipo médico está de pie 4 horas para realizar un procedimiento quirúrgico; y lo hace en vez de ir a jugar tenis, golf o cualquier otra actividad recreativa. Estas acciones muestran, además, que las razones institucionales se vinculan de manera crucial con las instituciones y con las reglas constitutivas que las regulan. Dichas razones, al igual que la intencionalidad colectiva, existen incluso cuando hay conducta que parece puramente individual. En este sentido, es importante recalcar que la sujeción a las reglas de los individuos no impide que persigan sus fines individuales, sino que deben hacerlo dentro de ciertos límites. Tal como ocurre en una sociedad constituida por dos individuos, en que cooperan para lucrar, este fin no puede ser contrario a ciertas "reglas del juego", como lo sería si dos competidores se coluden. En consecuencia, puede haber intencionalidad colectiva, incluso si se persigue el lucro, tal como Searle destaca con la "Escuela de Harvard 2", a propósito de cuándo hay cooperación genuina (SEARLE, 2010, p. 47-48). Pese a que su 
afán es lucrar, los miembros de tal Escuela han convenido cooperar para lograr este fin, y eso indica que hay intencionalidad colectiva.

Es claro que la cooperación, condición necesaria de la intencionalidad colectiva, es difícil de detectar en ciertas situaciones. En un evento de boxeo, por ejemplo, hay tal intencionalidad entre los boxeadores. Ambos están involucrados en una actividad deportiva de acuerdo con reglas específicas, y el apego a las "reglas del juego" promueve que se confíe en que el adversario hará lo que corresponde para obtener la victoria. Boxear implica no solo actuar de acuerdo con dichas reglas, sino que paradójicamente supone un sentido de cooperación, porque hay expectativas en ambas partes de lo que hará y no debe hacer el contrario. Esa cooperación, que surge del seguimiento de reglas, lleva consigo la generación de ámbitos de competencia para los participantes. De acuerdo con estos cada uno de ellos asumirá riesgos que deberá cargar por su cuenta, y otros en relación con los cuales puede confiar en que los demás obrarán del mismo modo. Las razones institucionales, a propósito de la confianza, fijan un "mínimo común" para moverse en el mundo, en el que no se acepta que cada individuo se presente como un "único". Tal mínimo común genera una "uniformidad de base" que puede exigirse para que todo funcione, lo cual está ciertamente ligado al correcto funcionamiento de las reglas.

Es importante tener en cuenta que lo que pasa con una orquesta, con un equipo de fútbol y con un par de boxeadores también puede extenderse al resto de la realidad social. Si aún caben dudas, considérese la siguiente situación, a propósito de la crucial relación entre cooperación, confianza e intencionalidad colectiva.

Alguien entra a un restaurante y ordena una cerveza. $\mathrm{Su}$ orden implica confiar, asumiendo tácitamente, que una serie de cosas ocurrirán en circunstancias normales. He aquí algunas de ellas:

i) El restaurante no ha adulterado la cerveza;

ii) Los mozos están capacitados para atender público;

iii) Los billetes del vuelto no son falsificados.

Aunque es posible que i, ii y iii resulten falsas, si los poderes deónticos funcionan correctamente, no dudamos si la cerveza ha sido adulterada, si los mozos están capacitados para servir o si los billetes de la caja son falsificados. Sostenemos, a propósito de esto, que dudar y desconfiar no son actitudes naturales en contextos como el descrito; por lo general, en la realidad social 
desconfiamos cuando hay razones fundadas para tener dudas acerca del funcionamiento de reglas y poderes deónticos.

Razones fundadas para la desconfianza surgen, por ejemplo, en situaciones excepcionales o de necesidad extrema, en las cuales no cabe esperar que los demás sigan reglas, y menos que pospongan la satisfacción de expectativas inmediatas. Piénsese, por ejemplo, en una situación de naufragio en que no hay suficientes botes salvavidas; supuesto en el cual ninguno de los siniestrados puede esperar que, por razones de buena crianza, los hombres cedan su lugar a las mujeres, o los jóvenes a los de mayor edad. Pero este tipo de situaciones, insistimos, no es lo que constituye una situación normal, con las expectativas que esta conlleva. En consecuencia, en circunstancias normales, donde operan poderes deónticos, no hay abuso de estos, ni nadie intenta priorizar la satisfacción de deseos e inclinaciones personales. Por el contrario, en una situación de funcionamiento normal de dichos poderes, con reglas que funcionan habitualmente, las personas cumplen con estas de manera responsable.

El hecho de que, por ejemplo, atrapar a una banda de falsificadores operando en un restaurante se convierta en noticia apoya que es razonable, incluso sensato, operar de acuerdo con el principio de la confianza. Lo mismo que esa acción dolosa sea perseguida y sancionada en aplicación de las normas vigentes, porque demuestra que se considera que ella altera (o puede alterar) una situación de confianza previa, y que hay que restablecer con la represión del hecho infractor.

Defendemos que la confianza es claramente una actitud social natural. Esta es un factor que facilita la intencionalidad colectiva, es decir, la cooperación entre agentes. La desconfianza y la duda, en cambio, la dificultan. Resulta interesante, con relación a esta diferencia, que en un sistema social en que las estructuras institucionales generan confianza, se promueve la existencia de más confianza. Por supuesto, lo anterior no quiere decir que en dicho sistema no puedan haber tramposos, embusteros y estafadores. Incluso, que estos tengan algún sentido de la colaboración para cometer delitos, lo cual podría hacer creer que la mafia es una institución (TUOMELA, 1997, p. 440). De seguro pueden existir casos como este, pero el punto es que actuamos primero asumiendo que las reglas y los poderes deónticos funcionan; no dudamos o desconfiamos a priori, porque resulta mucho menos complejo asumir que la trampa, la estafa y la mentira son excepcionales en un sistema social. En la 
confianza, justamente, se origina la obligación del seguimiento de reglas, tal como Luhmann (2005), Jakobs (2000) y Millas (2012, p. 358-359) destacan.

Luhmann, por ejemplo, sostiene que "donde hay confianza hay aumento de posibilidades para la experiencia y la acción, hay un aumento de la complejidad del sistema social y también del número de posibilidades que pueden reconciliarse con su estructura, porque la confianza constituye una forma más efectiva de reducción de la complejidad" (LUHMANN, 2005, p. 14). Esto confirma que es más simple asumir que los poderes deónticos, $y$ en general las reglas, funcionan correctamente. Ello porque la confianza simplifica el futuro abierto. Tal como Luhmann (2005, p. 33) recalca luego:

La complejidad del mundo futuro se reduce por medio del acto de confianza. Al confiar, uno se compromete con la acción como si hubiera solo ciertas posibilidades en el futuro. El actor une su futuro en el presente con su presente en el futuro. De esta manera ofrece a otras personas un futuro común, que no emerge directamente del pasado que ellas tienen en común, sino que contiene algo relativamente nuevo. (Cursivas nuestras).

Jakobs (2000), por otra parte, considera que la fuente de la confianza se da por medio de reglas que fijan estándares; estos se dirigen a portadores de roles donde los caracteres individuales de los sujetos, que están llamados a satisfacerlos, no son relevantes. La relación entre poderes deónticos y confianza se vincula con la seguridad, además. Tal como sostiene Millas, hay una crucial relación entre esta y las reglas, lo que se relaciona con el ámbito jurídico:

Saber o certeza, por una parte, y expectativa o confianza, por otra. El saber se refiere a la existencia de las normas jurídicas. Es nuestro conocimiento: a) de que hay ciertas normas que disponen tales o cuales conductas por modo impersonal y objetivo, y b) de que el orden así previsto, es generalmente observado. La confianza deriva de ese conocimiento y consiste en la fundada expectativa de una continua y prolongada vigencia del orden jurídico. No se trata aquí de esa certeza de conocimiento teórico respecto a la existencia y contenido de las normas, sino de la anticipación de lo que, probablemente, ocurrirá en vista de la actual vigencia del orden jurídico. Sin embargo, el valor práctico de esta probabilidad es tan grande que lo equiparamos a la certeza y arreglamos conforme a ella nuestra conducta. Solo así es posible que se constituya la situación de seguridad. (MILLAS, 2012, p. 359). 
En consecuencia, navegar en la realidad social requiere no solo de cooperación y del funcionamiento deontológico de las instituciones de acuerdo con sus reglas constitutivas. Se necesita además confiar, asumiendo que en circunstancias normales las personas se comportarán en función de reglas, derechos y deberes. Tal como argumentamos a continuación, la educación pública, en tanto producto de la intencionalidad colectiva general, justamente ayuda a consolidar las instituciones públicas que tienen como objetivo lo colectivo. Esto ayuda a conformar un círculo virtuoso, al incentivar el espacio de lo común, el locus del beneficio de todos.

\section{El CÍRCULO VIRTUOSO DE LA EDUCACIÓN PÚBLICA}

En la primera sección analizamos de qué forma el ser humano está inmerso en la realidad social, la cual no se reduce a una ontología objetiva. En la segunda mostramos cómo las instituciones se asocian con reglas y poderes deónticos, todo lo cual fortalece la confianza y promueve la mantención de estructuras institucionales. Con base en los análisis previos, en esta sección nos abocamos a mostrar que la educación pública, a diferencia de la privada, privilegia la lógica y el espacio de lo común. Ello ayuda a conformar un círculo virtuoso: la educación pública, al ser producto de la intencionalidad colectiva general, afianza las instituciones con miras a potenciar lo colectivo y lo común; las instituciones públicas resultantes de este proceso promueven el servicio público, y este, la educación pública.

La educación es una institución social, y se construye como cualquier otra bajo la fórmula $X$ cuenta como $Y$ en $C$. El acuerdo entre individuos determina que cierta actividad se entienda en un contexto determinado como educar. Lo que caracteriza esa institución es su finalidad: la búsqueda de la verdad; pero también su función: la formación de la juventud. La universalidad e inclusividad con que propende a ello es lo que caracteriza, de acuerdo con nuestra opinión, la educación pública frente a la privada. Y lo que explica que la misma ofrezca, a la sociedad, una fuente de fomento para la institucionalidad y el servicio público.

En la educación pública subyace una lógica que podríamos llamar institucional: no se identifica con uno o más sujetos concretos. No sirve a ningún interés particular, sino que al interés de todos. En ese sentido es general, e inclusiva. Ese carácter despersonalizado genera una garantía, una confianza, una expectativa de permanencia que no es posible predicar en relación con instituciones dependientes de una o más personas privadas. Las 
instituciones públicas no se encuentran a merced de intereses privados, de patrimonios particulares ni de cambios de circunstancias. Por lo mismo, esa confianza en las instituciones sociales genera expectativas que reafirman la vigencia de las instituciones públicas. Así, en la medida en que la educación pública muestra ese espacio y esa lógica de lo común se vuelve una fuente de ella; y quienes se han formado en ese mundo confían y desarrollan sus expectativas sobre la base de su estructura; de ese modo, potencian también, de manera subjetiva, su desarrollo.

A nuestro juicio, la filosofía socrática puede contar como un buen ejemplo de lo anterior, porque privilegia el ámbito de lo común por sobre lo personal y lo privado. El diálogo socrático es, precisamente, paradigmático, pese a la ironía y tensión que pueda exhibir, punto que retomaremos más abajo.

Sócrates es un importante antecedente en la Antigüedad de la relación entre enseñanza pública y el ámbito de lo común. Es posible sostener que este filósofo es quien institucionaliza la educación pública, pues su filosofía promueve un tipo de enseñanza inclusiva, que tiende a la búsqueda de la verdad y a la refutación de la falsedad. Para él la enseñanza no es mero traspaso de información, ni una relación de tutelaje; por el contrario, es diálogo en la polis. Este hace al ciudadano consciente de la importancia de la ley, creada por la intencionalidad colectiva general. De esta forma, Sócrates institucionaliza la inclusión del ciudadano en la ciudad, mediante la búsqueda de la verdad y el reconocimiento del nomos.

Nuestra interpretación de la filosofía socrática se enmarca en la discusión académica que ha suscitado su actitud en los diversos diálogos platónicos, desde los tempranos hasta el Menón y el Theetetos (BRICKHOUSE; SMITH, 2000). Ciertamente, parece haber una evolución de la enseñanza socrática desde los primeros diálogos hasta estos últimos. En aquellos hay tensión e ironía con los interlocutores, mientras que en estos hay preeminencia del método de la partera (BRICKHOUSE; SMITH, 2009). Esto por supuesto se relaciona con la teoría de Searle, porque hay cooperación entre Sócrates y sus interlocutores, incluso si hay una suerte de "boxeo" filosófico en los primeros diálogos. Dicha cooperación es fundamento suficiente para sostener que Sócrates busca la cooperación y luego, la intencionalidad colectiva para crear algo que, sin esa cooperación, sería imposible. El diálogo es justamente una muestra de esto, por tener un cariz casi institucional. 
Sócrates es inclusivo, siempre está abierto a los demás. Y ello enseña que su filosofía, con la búsqueda de la verdad, reafirma lo colectivo, lo ciudadano, por sobre lo individual. El siguiente párrafo es iluminador en este sentido:

Yo no he sido jamás maestro de nadie. Si cuando yo estaba hablando y me ocupaba de mis cosas, alguien joven o viejo, deseaba escucharme, jamás se lo impedí a nadie. Tampoco dialogo cuando recibo dinero y dejo de dialogar si no lo recibo, antes bien me ofrezco, para que me pregunten, tanto al rico como al pobre, y lo mismo si alguien prefiere responder y escuchar mis preguntas. Si alguno de estos es luego un hombre honrado o no lo es, no podría yo en justicia incurrir en culpa; a ninguno de ellos les ofrecí nunca enseñanza alguna ni les instruí. (PLATÓN, 1981, p. 173, 32a-b, énfasis nuestro).

Sin embargo, aquí las palabras de Sócrates deben interpretadas con cuidado. Además de posible la ironía, tómese en cuenta el comentario que Jaspers hace en relación con esta: "Intenta que sus estudiantes se independicen de él para que sean dependientes de su ser; se disfraza en paradojas, haciéndose inaccesible" (SMART, 1959, p. 50). En consecuencia, estimamos que negar su condición de educador es parte de la ironía que emplea, para evitar el tutelaje, y así no detener la búsqueda de la verdad.

Justamente, sus consideraciones acerca de la relación entre dicha búsqueda y la acción guiada por la virtud, se relacionan con el reconocimiento de la ley, y con como este significa un compromiso de los ciudadanos con la polis. Obedecer la ley requiere mucho más que pura instrucción para tales efectos: se necesita de cooperación con la ciudad, posponiendo deseos e inclinaciones personales. Un ejemplo de esto es que jueces y oradores deben decir la verdad (PLATÓN, 1981, p. 149, 17d).

Dicho compromiso requiere posponer deseos e inclinaciones personales, incluso cuando, por miedo, se siente el deseo de evitar la muerte a cualquier costa:

En efecto, ni ante la justicia ni en la guerra, ni yo ni ningún otro deben maquinar cómo evitar la muerte a cualquier precio. Pues también en los combates muchas veces es evidente que se evitaría la muerte abandonando las armas y volviéndose a suplicar a los perseguidores. Hay muchos medios en cada ocasión de peligro de evitar la muerte, si se tiene la osadía de ser y decir cualquier cosa. Pero no es difícil atenienses evitar la muerte, es mucho más difícil evitar la maldad; en efecto, corre más deprisa que la muerte. (PLATÓN, 1981, p. 182, 39a). 
También recalca a Critón, a propósito de su condena a muerte, que el ciudadano está obligado a cumplir con la ley, porque esta debe respetarse tanto como la patria y los padres:

Ciertamente no serían iguales tus derechos respecto a tu padre y respecto a tu dueño, si lo tuvieras, como para que respondieras haciéndoles lo que ellos te hicieran, insultando a tu vez al ser insultado, o golpeando al ser golpeado, y así sucesivamente. ¿Te sería posible, en cambio, hacerlo con la patria y las leyes, de modo que si nos proponemos matarte, porque lo consideramos justo, por tu parte intentes, en la medida de tus fuerzas, destruimos a nosotras, las leyes, y a la patria, y afirmes que al hacerlo obras justamente, tú, el que en verdad se preocupa de la virtud? ¿Acaso eres tan sabio que te pasa inadvertido que la patria merece más honor que la madre, que el padre y que todos los antepasados, que es más venerable y más santa y que es digna de la mayor estimación entre los dioses y entre los hombres de juicio? (PLATÓN, 1981, p. 205-206, 51a-c, énfasis nuestro).

De esto se sigue que la ley es un compromiso que debe asumirse. Una justificación para tal interpretación es que los ciudadanos que se comprometen con ella, en la medida que lo han hecho, han sido partícipes de los bienes que han florecido gracias a su imperio. Por ejemplo, con la educación que han recibido. No es casual, entonces, que Sócrates defienda cumplir con la ley, fundamento de la polis ateniense; ni que de su filosofía pueda inferirse que la educación debe ser una institución inclusiva, orientada a la búsqueda de la verdad, con una enseñanza que enseñe una racionalidad por sobre la satisfacción de deseos e inclinaciones personales.

En clave contemporánea, la educación pública, por ser parte del servicio público y por tener el mismo origen que la ley, reafirma la intencionalidad colectiva general y, con este, un compromiso ciudadano. A su vez, ello lleva al afianzamiento de los poderes deónticos y la confianza, tal como analizamos en la sección previa. Si bien la educación privada también es compatible con el reconocimiento de la ley y con el afianzamiento de las instituciones, en la medida que es producto de la intencionalidad colectiva de individuos, siempre arriesga desviar la atención a la satisfacción de los intereses de estos. La intencionalidad colectiva general, que es fundamento de la educación pública, es en cambio afín a la primacía de lo colectivo por sobre lo individual. Dado el bien común que también salvaguarda, la educación pública es reconocida por toda la ciudadanía, incluso por aquellos que estiman superior la educación privada. En efecto, reconocer una institución pública como 
la educación pública no implica aceptarla con entusiasmo, sino que solo se requiere ir junto a la misma, punto que Searle (2010, p. 97) ha enfatizado con respecto al reconocimiento de las instituciones y a como este se relaciona con la cooperación. Podemos cooperar con la educación pública, financiarla por ejemplo, sin que haya una entusiasta aceptación de la misma.

Si las consecuencias "institucionales" de la educación pública y la privada no parecen aún convincentes, piénsese en el sentido de cooperación que implica un proyecto educativo privado y uno público. Por ejemplo, la diferencia que existe entre el colegio de una comunidad de inmigrantes europeos de un credo religioso específico, católico por ejemplo, y el de un liceo público. Mientras que el primero se orientará a cooperar para preservar valores específicos, y a una religión particular, solo el segundo tendrá apertura hacia la ciudadanía en su totalidad: no solo recibirá inmigrantes junto con los locales, su enseñanza laica se orientará a lo colectivo y, por tanto, constituirá un espacio para lo común, o lo que es lo mismo, para la inclusión de toda la comunidad. Esa apertura, que ya se vislumbra en Sócrates y sobre la que insiste Newman (1996, p. 106) a propósito del conocimiento y la universidad, es precisamente la marca de la educación pública: la universalidad de la enseñanza, mediante la inclusión, y la diversidad de los educandos. Ambos elementos hacen que, sin perjuicio de las razones que se esgrimen para que la educación pública no sea gratuita para todos, siempre será deseable que, si hay intencionalidad colectiva general que la respalde, lo sea. Así se garantiza la inclusión de todos los miembros de la comunidad.

Por todas las razones expuestas aquí, en la civilización resulta difícil que se prescinda de la educación pública. En efecto, un estado sin esta es como un pater familia sin herederos, o como un gobierno sin juventud a quien enseñar y sobre la cual proyectarse. Como Sócrates y sus hijos, un pater familia se proyectará en sus herederos, tanto como un gobierno en la juventud, razón suficiente para educarla. La educación pública es, por tanto, una instancia para satisfacer la intencionalidad colectiva general y el consiguiente origen del fortalecimiento de las instituciones públicas. La lógica de lo común, que se implementa gracias a la intencionalidad colectiva general, motiva dedicar esfuerzos a la enseñanza pública, con lo cual, argumentamos, se completa el círculo virtuoso de esta. 


\title{
Conclusiones
}

Gracias a la intencionalidad colectiva general surgen las instituciones públicas. El espacio de lo común, producto de aquella, hace difícil su reducción ontológica objetiva. Como hemos argumentado, cuando las reglas constitutivas y los poderes deónticos funcionan correctamente, se produce un incremento de la confianza, y el reconocimiento y mantención de las estructuras institucionales. Hemos destacado, asimismo, que una institución pública en particular, la educación pública, es producto de la mencionada intencionalidad colectiva general. Si bien la educación privada puede desarrollar las habilidades y las capacidades de las personas, en tanto se origina en la intencionalidad colectiva de individuos, arriesga satisfacer solo los deseos e inclinaciones de estos. La pública, en cambio, se compromete con los intereses de la ciudadanía en general como, por ejemplo, el reconocimiento de la ley. Sócrates es quien institucionaliza la educación pública en este preciso sentido. De ahí, hemos examinado, se genera un círculo virtuoso: la educación pública, por su origen, contribuye a implementar la lógica de lo común y del servicio público. Este motiva dedicar esfuerzos a la enseñanza pública.

GONZÁLEZ F., R. A.; KRAUSE M., M. S. Social ontology and the virtuous circle in public education. Trans/form/ação, Marília, v. 41, n. 2, p. 157-176, Abr./Jun., 2018.

\begin{abstract}
In this article, we argue that the public or private nature of education strongly influences institutions in social reality. We first show how we dwell in a world of institutions whose creation and maintenance is governed by rules and deontic powers. Importantly, these are not reducible by ontologically objective sciences. Secondly, we claim that collective intentionality requires trust, which arises as the aforementioned powers are deployed under normal conditions, for example, when rules are observed. Finally, we argue that public education is an institution that, unlike private education, works for the common good. Socrates is an example of this, as his philosophy seeks not only truth, but also the acknowledgement of law rather than the immediate satisfaction of desires and personal inclinations. The virtuous circle can thus be described as follows: public education, which aims to benefit all, strengthens social institutions that are aimed at common good, amongst them public service.
\end{abstract}

KeYwords: Public education. Deontic powers. Institutions. Institutional reasons. 


\section{REFERENCIAS}

BRICKHOUSE, T. C.; SMITH, N. The philosophy of Socrates. Boulder, Colorado: Westview Press, 2000.

. Socratic teaching and socratic method. In: SIEGEL, H. (Ed.). The Oxford handbook of philosophy of education. New York: OUP, 2009. p. 177-194.

JAKOBS, G. Sobre la génesis de la obligación jurídica. Doxa, n. 23, p. 323- 348, 2000.

JASPERS, J. The idea of the university. Boston: Beacon, 1959.

LUHMANN, N. Confianza. Barcelona: Anthropos, 2005.

MILLAS, J. Filosofia del derecho. Santiago de Chile: Ediciones Universidad Diego Portales, 2012.

NEWMAN, J. H. The idea of a university. London: Yale University Press, 1996.

PLACE, U. T. Is consciousness a brain process? Journal of Psychology, v. 47, n. 1, p. 4450, 1956.

PLATÓN. Diálogos: Apología, Critón, Eutifrón, Ión, Lisis, Cármides, Hipias menor, Hipias mayor, Laques, Protágoras. Madrid: Gredos, 1981.

. La república. Madrid: Centro de Estudios Político-Constitucionales, 2006.

RAKOCZY, H. Taking fiction seriously: Young children understand the normative structure of joint pretence games. Developmental Psychology, v. 44, n. 4, p. 1195-1201, jul. 2008.

RAKOCZY, H; TOMASELLO, M. The ontogeny of social ontology: Steps to shared intentionality and status functions. In: TSOHATZIDIS, S. (Ed.). Intentional acts and institutional facts. Dordrecht: Springer, 2007. p. 113-137.

SEARLE, J. Intentionality and its place in nature. Synthese, v. 61, n. 1, p. 3-16, 1984. Reimpreso en: . Consciousness and language. Cambridge: Cambridge University Press, p. 77-89.

. La construcción de la realidad social. Barcelona: Paidós, 1997.

Making the social world: the structure of human civilization. Oxford:

OUP, 2010 .

SMART, J. J. C. Sensations and brain processes. Philosophical Review, v. 68, n. 2, p. 141$156,1959$.

TUOMELA, R. Searle on social institutions. Philosophy and Phenomenological Research, v. 57, n. 2, p. 435-441, 1997.

Recebido: 09/07/2015

Aprovado: 20/11/2016 